\title{
Metabotropic Glutamate Receptors Induce a Form of LTP Controlled by Translation and Arc Signaling in the Hippocampus
}

\author{
Hui Wang, ${ }^{1}$ Alvaro 0. Ardiles, ${ }^{1,2}$ Sunggu Yang, ${ }^{1}$ Trinh Tran, ${ }^{1}$ Rafael Posada-Duque, ${ }^{1}$ Gonzalo Valdivia,,${ }^{1,2}$ Min Baek, ${ }^{1}$ \\ Yang-An Chuang, ${ }^{3}{ }^{\circledR}$ Adrian G. Palacios, ${ }^{2}{ }^{\oplus}$ Michela Gallagher, ${ }^{3}$ Paul Worley, ${ }^{4}$ and ${ }^{\circledR}$ Alfredo Kirkwood ${ }^{1,4}$ \\ ${ }^{1}$ Mind/Brain Institute, Johns Hopkins University, Baltimore, Maryland 21218, ${ }^{2}$ Centro Interdisciplinario de Neurociencia de Valparaiso, Universidad de \\ Valparaiso, Chile, ${ }^{3}$ BCMB-Neuroscience Johns Hopkins Medical School, Baltimore, Maryland 21205, ${ }^{4}$ Department of Brain and Psychological Sciences, \\ Johns Hopkins University, Baltimore, Maryland 21218, and 5Department of Neuroscience, Johns Hopkins University, Baltimore, Maryland 21205
}

Activity-dependent bidirectional modifications of excitatory synaptic strength are essential for learning and storage on new memories. Research on bidirectional synaptic plasticity has largely focused on long-term potentiation (LTP) and long-term depression (LTD) mechanisms that rely on the activation of NMDA receptors. In principle, metabotropic glutamate receptors (mGluRs) are also suitable to convert synaptic activity into intracellular signals for synaptic modification. Indeed, dysfunction of a form of LTD that depends on Type I mGluRs (mGluR-LTD), but not NMDARs, has been implicated in learning deficits in aging and mouse models of several neurological conditions, including Fragile X syndrome and Alzheimer's disease. To determine whether mGluR activation can also induce LTP in the absence of NMDAR activation, we examined in hippocampal slices from rats and mice, an NMDAR-independent form of LTP previously characterized as dependent on voltage-gated $\mathrm{Ca}^{2+}$ channels. We found that this form of LTP requires activation of Type I mGluRs and, like mGluR-LTD but unlike NMDAR-dependent plasticity, depends crucially on protein synthesis controlled by fragile X mental retardation protein and on Arc signaling. Based on these observations, we propose the coexistence of two distinct activity-dependent systems of bidirectional synaptic plasticity: one that is based on the activity of NMDARs and the other one based on the activation of mGluRs.

Key words: arc; bidirectional; metabotropic glutamate receptors; protein synthesis; synaptic plasticity; translation

Significance Statement

Bidirectional changes of synaptic strength are crucial for the encoding of new memories. Currently, the only activity-dependent mechanism known to support such bidirectional changes are long-term potentiation (LTP) and long-term depression (LTD) forms that relay on the activation of NMDA receptors. Metabotropic glutamate receptors (mGluRs) are, in principle, also suitable to trigger bidirectional synaptic modifications. However, only the mGluR-dependent form of LTD has been characterized. Here we report that an NMDAR-independent form of LTP, initially characterized as dependent on voltage-gated $\mathrm{Ca}^{2+}$ channels, also requires the activation of mGluRs. These finding suggest the coexistence of two distinct activity-dependent systems of bidirectional synaptic plasticity: one that is based on the activity of NMDARs and the other one based on the activation of mGluRs.

\section{Introduction}

The capacity of synapses to undergo lasting increases or decreases in strength in response to activity patterns is thought to be essen-

Received March 5, 2015; revised Dec. 1, 2015; accepted Dec. 23, 2015.

Author contributions: H.W., P.W., and A.K. designed research; H.W., A.O.A., S.Y., T.T., R.P.-D., G.V., M.B., Y.-A.C., and P.W. performed research; A.G.P. and M.G. contributed unpublished reagents/analytic tools; H.W., A.O.A., S.Y., G.V., M.B., and A.K. analyzed data; S.Y., A.G.P., and A.K. wrote the paper.

This work was supported by NIH/NIA Grants R01AG034606 to A.K. and P01-AG09973 to M.G., and Instituto Cientifico Milenio Grant ICM-P09-022-F to A.G.P. We thank Hey-Young Lee for valuable discussions and comments. The authors declare no competing financial interests.

Correspondence should be addressed to Dr. Alfredo Kirkwood, Mind Brain Institute, Johns Hopkins University, 338 Krieger Hall, 3400 N. Charles Street, Baltimore, MD 21218. E-mail: kirkwood@jhu.edu. tial for the processes of learning and memory formation. Currently, the most comprehensive (and most studied) models of bidirectional synaptic modification are activity-dependent forms of long-term potentiation (LTP) and long term-depression (LTD) that require the activation NMDA receptors to initiate insertion or removal of AMPA receptors from the synapse (Huganir and Nicoll, 2013). The focus on NMDAR-dependent LTP and LTD (NMDAR-LTP/D) results in part because their molecular mechanisms have been worked out to a great detail, 
particularly in the CA1 region of the hippocampus, and in part because of the wealth of evidence implicating these forms of plasticity in multiple learning processes (Morris, 2013). In this study, we examined the possibility that the metabotropic glutamate receptors (mGluRs) can also support bidirectional changes in synaptic strength, independently of NMDARs.

It is well established that stimulation of Type I mGluRs (mGluR1 and mGluR5) alone can induce LTD expressed as endocytosis of synaptic AMPA receptors (Lüscher and Huber, 2010). Mechanistically, this mGluR-dependent form of LTD (mGluR-LTD) and NMDAR-LTD are widely different. They can operate on different subunits of the AMPA receptor (Casimiro et al., 2011); and while the induction of mGluR-LTD requires intact protein synthesis and it is under the control of Arc/arg3.1 signaling, the induction of NMDAR-LTD does not (Huber et al., 2000; Park et al., 2008; Waung et al., 2008). Importantly, the dysregulation of mGluR-LTD has clear functional consequences as it has been implicated in learning deficits associated with aging (Lee et al., 2005; Boric et al., 2008; Yang et al., 2013), as well as in neuropathological conditions, including fragile $\mathrm{X}$ mental retardation (Huber et al., 2002; Bear et al., 2004) and Alzheimer's disease (Hsieh et al., 2006).

In contrast to the well-characterized mGluR-LTD, the case for mGluR-dependent LTP has been more elusive. Although Type I mGluRs modulate the induction of NMDAR-LTP in multiple synapses (Abraham, 2008), LTP that exclusively requires mGluRs but not NMDARs has only been reported in the subiculum (Fidzinski et al., 2008), where it is typically "masked" by NMDARLTD. This paucity of information prompted us to determine whether activation mGluRs can induce not only LTD but also LTP in the absence of NMDAR. An attractive candidate model to examine was a form of LTP that depends on L-type voltage-gated calcium channels (VGCC-LTP) (Grover and Teyler, 1990). VGCC-LTP is typically induced under NMDAR blockade with tetanic stimulation of higher frequency and longer duration than the one used for NMDAR-LTP (Grover and Teyler, 1990). By analogy with mGluR-LTD induction, which also requires stronger stimulation than NMDAR-LTD, we reasoned that the higher induction threshold in VGCC-LTP might reflect the need to build up glutamate at the periphery of the synapse to recruit the largely perisynaptic mGluRs. Our examination of this form of LTP indicated that is indeed dependent on Type I mGluRs and, like mGluR-LTD but unlike NMDAR-LTP, it also requires protein synthesis and Arc signaling.

\section{Materials and Methods}

Animals. Animals used were 4-month and 20-month-old male Long-Evans rats or 2-month-old male Arc/Arg3.1 KO and Fmr1 KO mice. Both mouse lines were kept in a BL6 background. Hippocampal slices $(400 \mu \mathrm{m})$ were prepared as described previously (Yang et al., 2013) in ice-cold dissection buffer containing the following: $212.7 \mathrm{~mm}$ sucrose, $2.6 \mathrm{~mm} \mathrm{KCl}, 1.23 \mathrm{~mm}$ $\mathrm{NaH}_{2} \mathrm{PO}_{4}, 26 \mathrm{~mm} \mathrm{NaHCO}, 10 \mathrm{~mm}$ dextrose, $3 \mathrm{~mm} \mathrm{MgCl}_{2}$, and $1 \mathrm{~mm} \mathrm{CaCl}$ bubbled with a mixture of $5 \% \mathrm{CO}_{2}$ and $95 \% \mathrm{O}_{2}$. For recordings in aged rats, we used transcardial perfusion before isolating the brain (Yang et al., 2013). All the procedures were approved by the Johns Hopkins University animal care committee. The slices were recovered for $1 \mathrm{~h}$ at room temperature in ACSF as follows: $124 \mathrm{~mm} \mathrm{NaCl}, 5 \mathrm{~mm} \mathrm{KCl}, 1.25 \mathrm{~mm} \mathrm{NaH}_{2} \mathrm{PO}_{4}, 26 \mathrm{~mm}$ $\mathrm{NaHCO}_{3}, 10 \mathrm{~mm}$ dextrose, $1.5 \mathrm{~mm} \mathrm{MgCl}_{2}$, and $2.5 \mathrm{~mm} \mathrm{CaCl}_{2}$ bubbled with a mixture of $5 \% \mathrm{CO}_{2}$ and $95 \% \mathrm{O}_{2}$.

Synaptic responses. Synaptic responses were evoked with $0.2 \mathrm{~ms}$ pulses $(10-80 \mu \mathrm{A})$ delivered through concentric bipolar stimulating electrodes (FHC) or theta glass micropipettes filled with ACSF, recorded extracellularly in CA1 or CA3 stratum radiatum, and quantified as the initial slope of the field potential. Baseline responses were recorded at $0.033 \mathrm{~Hz}$ using a stimulation intensity that evoked a half-maximal response, defined as the maximal response without a population spike (pop-spike). Slices were discarded when the popspike appeared in the initial rising phase (an indication of hyperexcitability), when paired-pulse facilitation at a $50 \mathrm{~ms}$ interval was less than $\sim 10 \%$ (i.e., response $2 /$ response $1<1.1$ ), or when the baseline was not stable ( $>5 \% \mathrm{drift}$ ). High-frequency tetanus consisted of four $200 \mathrm{~Hz}$ epochs $(0.5 \mathrm{~s})$ delivered at $0.2 \mathrm{~Hz}$ in the presence of an NMDA receptor antagonist (100 $\mu \mathrm{M} \mathrm{D}, \mathrm{L}-\mathrm{APV})$. Under our experimental conditions, this protocol induces robust LTP in Long-Evans rats in both CA1 (Boric et al., 2008) and CA3 synapses (Yang et al., 2013). Theta burst stimulation (TBS) consisted of 4 or 6 theta epochs delivered at $0.1 \mathrm{~Hz}$. Each epoch, in turn, consisted of 10 trains of 4 pulses (at 100 $\mathrm{Hz}$ ) delivered at $5 \mathrm{~Hz}$. LTP magnitude was calculated as the average (normalized to baseline) of the responses recorded 50-60 min after conditioning stimulation, corresponding to the early phase of LTP (to distinguish it from late LTP). Drugs included 2-Methyl-6(phenylethynyl)pyridine (MPEP), LY-367385, (2S)- $\alpha$-Ethylglutamic acid (EGLU), anisomycin, (2R)-amino-5-phosphonovaleric acid (APV), and nifedipine from Tocris Bioscience; all other chemicals were from Sigma or Fisher Scientific.

Immunoblot analysis. Western blot was performed using a previously published protocol (Zhang et al., 2015). Slices were solubilized in cold $\left(4^{\circ} \mathrm{C}\right)$ PBS buffer containing $1 \%$ Triton, mM EDTA, 5 mm EGTA, and inhibitors of proteases (Roche, 11873580001) and phosphatases (Roche, 4906837001). After sonication, the lysates were gently mixed for $30 \mathrm{~min}$ and centrifuged at $13,200 \times g$ for $15 \mathrm{~min}$ at $4^{\circ} \mathrm{C}$. The supernatant was collected and mixed with Laemmli buffer for further immunoblotting.

Samples $(3.75 \mu \mathrm{g})$ were loaded onto $4 \%-12 \%$ precast gels (Novex, WG1403A) in a scrambled order-to minimize uneven blotting and ran for $2.5 \mathrm{~h}$ at $120 \mathrm{~V}$. Blots were transferred overnight to PVDF membranes at $40 \mathrm{~V}$ and blocked with 3\% BSA in TBST buffer for $1 \mathrm{~h}$. After proper washing, the membranes were incubated with HRP-linked secondary antibodies for $1 \mathrm{~h}$ at room temperature. The antibodies used include the following: anti-Arc monoclonal antibody (Dr. Paul Worley, 1:1000), HRP-linked anti-mouse IgG antibody (GE Life Science, NA931V, 1:1500), HRP-linked anti-rabbit IgG antibody (GE Life Science, NA934V), and peroxidase-conjugated anti$\beta$-actin antibody (Sigma, 1: 3000). The developed films were imaged and quantified (at $45 \mathrm{kDa}$ for Arc, and $42 \mathrm{kDa}$ for $\beta$-actin) with ImageJ tools (Zhang et al., 2015). All protein bands were normalized to $\beta$-actin in the same samples.

Statistical significance. Statistical significance was evaluated using Prism GraphPad software. The specific tests used were as follows: the two-tailed Mann-Whitney rank test for two sample comparisons and the Kruskal-Wallis test followed by a Dunn's correction for multiple comparisons. Data are mean \pm SEM.

\section{Results}

The central aim of the study was to determine whether mGluRs could induce LTP in the CA3 $\rightarrow$ CA1 synapses in the absence of NMDAR activation. To that end, we tested whether the NMDAR-independent form of LTP initially characterized as VGCC-LTP requires the activation of mGluRs. Therefore, unless otherwise noted, in these studies we recorded CA3 $\rightarrow$ CA1 synaptic responses as fEPSP in hippocampal slices from adult (2-4 month) Long-Evans rats, and LTP was induced with a highfrequency tetanus in the presence of $100 \mu \mathrm{M}$ APV to block NMDA receptors (see Materials and Methods).

\section{VGCC-LTP induction requires mGluR stimulation and protein synthesis}

We first tested the effects of blocking the activation of mGluRs on VCCG-LTP using a combination of mGluR antagonists known to block mGluR-LTD. The combination included $10 \mu \mathrm{M}$ MPEP (against mGluR5) and LY-367385 at a high dose (100 $\mu \mathrm{M})$ that blocks all Type I mGluRs (Volk et al., 2006). As shown in Figure $1 A$, LTP measured at $60 \mathrm{~min}$ after tetanus was substantial (132 \pm 
A

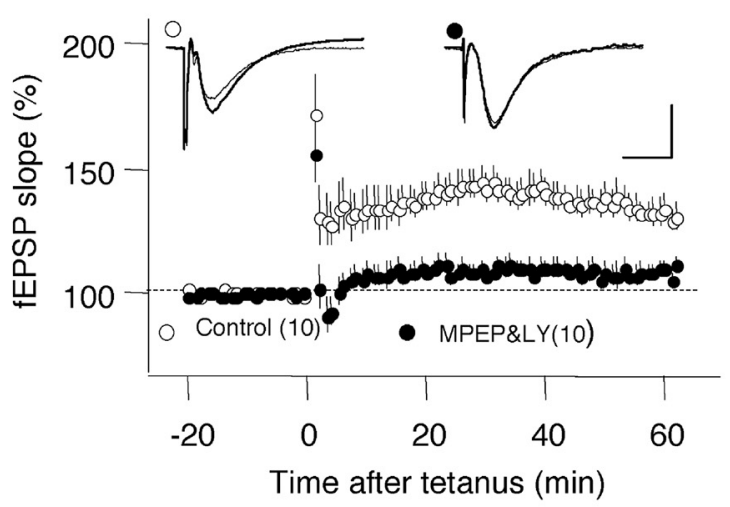

C

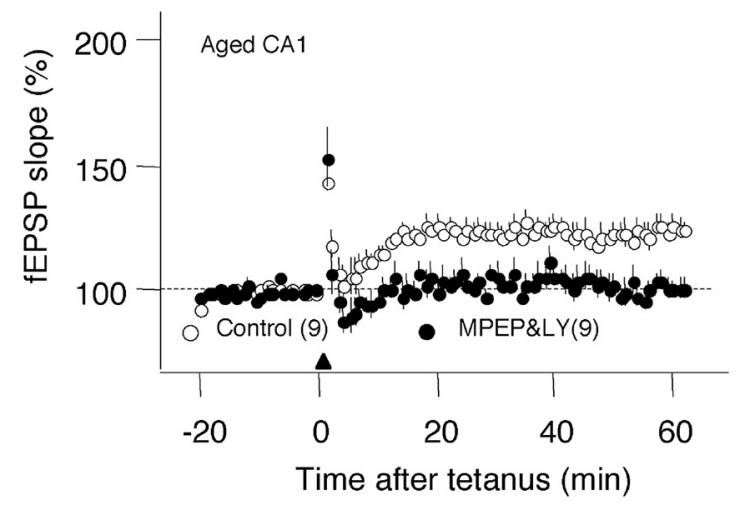

B

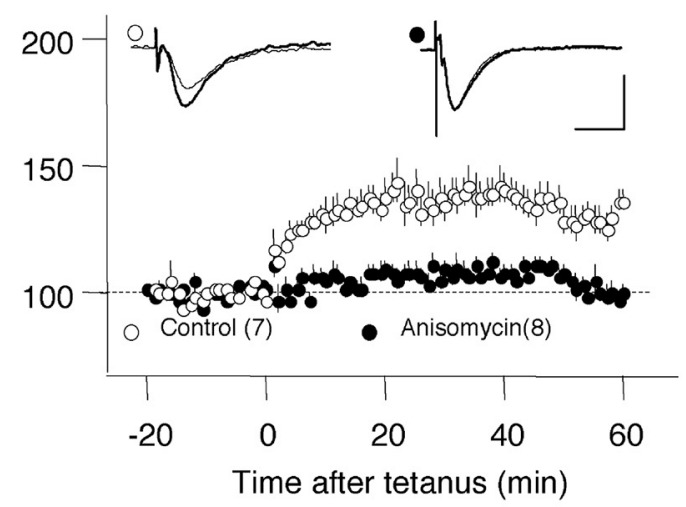

D

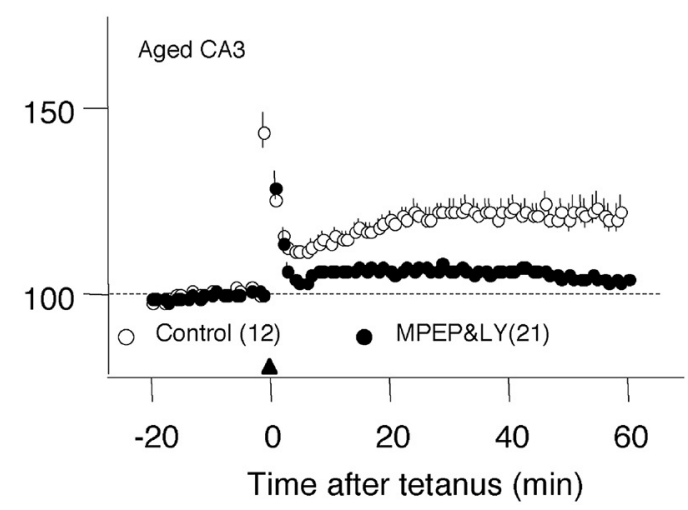

Figure 1. Induction of non-NMDAR-LTP in hippocampal pathways depends on mGluR and protein synthesis. $A, A 200 \mathrm{~Hz}$ tetanus delivered in the presence of $100 \mu \mathrm{m}$ APV induces robust LTP of the CA3 $\rightarrow$ CA1 field EPSPs (open circles), which is blocked by the addition of antagonists to Type I mGluRs ( $100 \mu \mathrm{m}$ LY-367385 and $10 \mu \mathrm{M}$ MPEP; filled circles). $\boldsymbol{B}$, LTP induced by the $200 \mathrm{~Hz}$ tetanus in APV is blocked by the protein synthesis inhibitor anisomycin (10 $\mu \mathrm{m})$. Open circles represent control DMSO. Filled circles represent anisomycin. $\boldsymbol{A}, \boldsymbol{B}$, Superimposed traces represent example experiments. Each trace is the average of 10 responses recorded before (thin traces) and 60 min after the tetanus (thick traces). Calibration: $1 \mathrm{mV}, 10 \mathrm{~ms}$. C, $\boldsymbol{D}$, In slices from aged rats ( $18-20 \mathrm{months}$ ), the $200 \mathrm{~Hz}$ LTP is also blocked by mGluR antagonists in both CA3 $\rightarrow$ CA1 synapses $(\boldsymbol{C})$ and in CA3 $\rightarrow$ CA3 synapses $(\boldsymbol{D})$. The number of experiments is indicated in parentheses.

$4 \%, n=10$ slices) in control conditions (only APV) but negligible in the presence of all antagonists (APV plus MPEP and LY-12436: LTP $=108 \pm 1 \%, n=10$ slices $)$. These differences were significant (Mann-Whitney: $p=0.0011$ ), indicating that this form of LTP, initially characterized as VCCG-LTP, is indeed an mGluRdependent form of LTP (mGluR-LTP). Hence, from here on, we refer to it as mGluR-LTP. Next, we asked whether, as in the case of mGluR-LTD (Volk et al., 2006), it is necessary to coapply both antagonists to block mGluR-LTP. We found that mGluR-LTP was not blocked by either MPEP (control: $126 \pm 8 \%, n=11$; MPEP: $123 \pm 7, n=15, p=0.99$ ) or LY-367385 (control: $133 \pm$ $8, n=14 ; \mathrm{LY}-12436: 125 \pm 5, n=20 ; p=0.500)$ applied alone (not shown), suggesting that Type I receptors can substitute each other in supporting LTP. On the other hand, the Type II antagonist EGU $(10 \mu \mathrm{M})$ did not affect mGluR-LTP (control: $128 \pm 7$, $n=12$; EGLU: $134 \pm 5, n=10 ; p=0.500)$. Together, the results strongly suggest that mGluR-LTP depends specifically on the activation of Type I mGluRs.

A defining feature of mGluR-LTD that distinguishes it from NMDAR-LTD is its strict requirement on normal protein translation (Huber et al., 2000). We examined, therefore, whether this is also the case with mGluR-LTP. We found that incubation with protein synthesis inhibitor anisomicyn $(10 \mu \mathrm{M}$ starting at least 30 min prior collecting baseline and throughout the experiment) severely prevented the induction of mGluR-LTP (Fig. $1 B$; anisomycin: $108 \pm 7 \%, n=7$; DMSO control: $129 \pm 6 \%, n=7 ; p=$ 0.0011). Together, the results indicate that the induction of
mGluR-LTP, like mGluR-LTD, depends on both stimulation of Type I mGluRs and intact protein synthesis.

An important motivation for the present study was the observation that, during aging, the integrity of mGluR-dependent plasticity is critical for maintaining youthful learning performance (Lee et al., 2005; Boric et al., 2008; Yang et al., 2013). Importantly, learning performance in aged individuals correlates positively with the magnitude of LTP induced with VGCC-LTP protocols in both the CA3 $\rightarrow$ CA1 and the $\mathrm{CA} 3 \rightarrow \mathrm{CA} 3$ hippocampal pathways. It was of interest, therefore, to confirm the mGluR dependence of this type of LTP in late aging. We found that, in slices from old rats (20-24 months), the Type I mGluR antagonist combination $(10 \mu \mathrm{M}$ MEP and $100 \mu \mathrm{M}$ LY 367385) prevents LTP induced with VGCC-LTP protocols in both the CA3 $\rightarrow$ CA1 pathway (Fig $1 C$ : control $124 \pm 5 \%, n=8$; antagonists: $103 \pm 1 \%, n=9$; $p=0.0011$ ) and in the CA3 $\rightarrow$ CA3 pathway (Fig $1 D$; control, $122 \pm 4 \%, n=16$; antagonist, $104 \pm 1 \%, n=21 ; p<0.001)$, indicating that the strict mGluR dependence of this type of LTP is maintained during aging.

\section{mGluR-LTP and NMDAR-LTP are not independent in the $\mathrm{CA} 3 \rightarrow \mathrm{CA} 3$ pathway}

Previous studies established that the nifedipine-sensitive and APV-sensitive components of LTP induced by the $200 \mathrm{~Hz}$ protocols (mGluR-LTP and NMDAR-LTP) are largely additive in both the $\mathrm{CA} 3 \rightarrow \mathrm{CA} 1$ and the $\mathrm{CA} 3 \rightarrow \mathrm{CA} 3$ pathways (Grover and Teyler, 

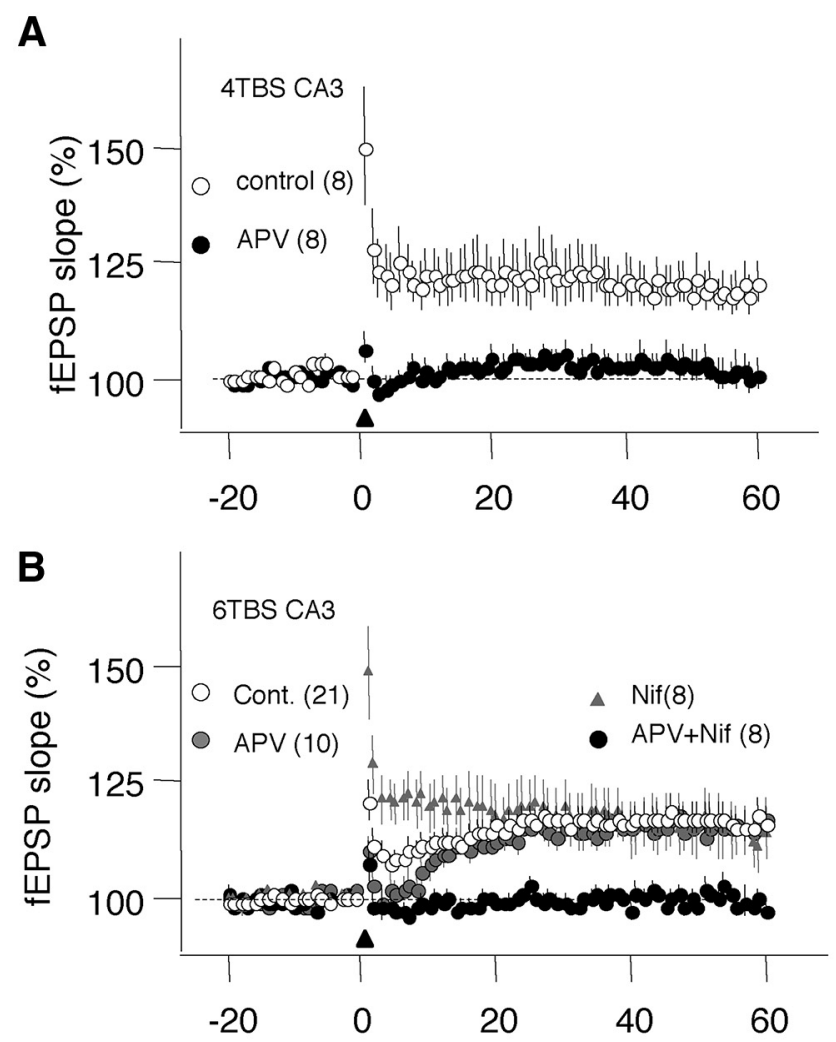

C

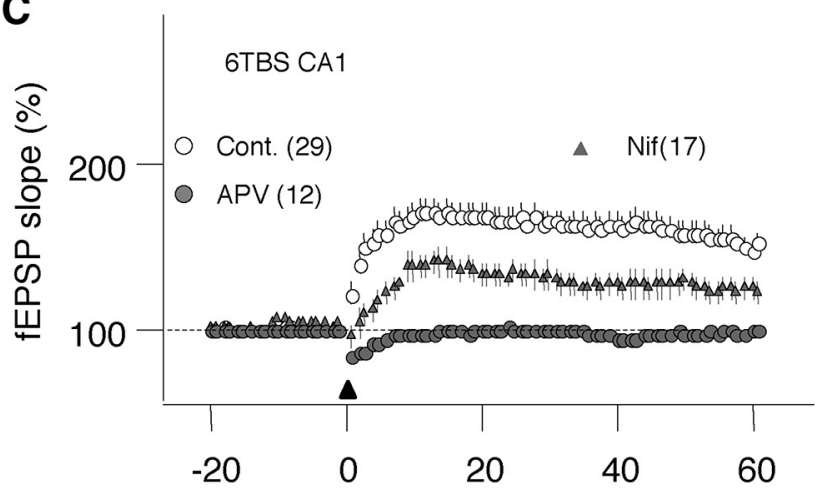

Time after TBS (min)

Figure 2. TBS induces mGluR-LTP in CA3 $\rightarrow$ CA3 synapses. $A$, Four TBS epochs (open circles) induce a form of LTP that is completely blocked by $100 \mu \mathrm{m} \mathrm{APV} \mathrm{(filled} \mathrm{circles).} \boldsymbol{B}$, LTP induced with 6 TBS epochs (open circles) is not blocked by either $100 \mu \mathrm{m} \mathrm{APV} \mathrm{(gray} \mathrm{circles)} \mathrm{or} 10 \mu \mathrm{m}$ nifedepine (gray triangles), yet it is completely blocked by the coapplication of $100 \mu \mathrm{m}$ APV and $10 \mu \mathrm{m}$ nifedepine (black circles). C, In CA3 $\rightarrow$ CA1 synapses, LTP induced with 6 TBS (open circles) is partially blocked by $10 \mu \mathrm{m}$ nifedepine (black triangles) and completely blocked by 100 $\mu \mathrm{m}$ APV (black circles). The number of experiments is indicated in parentheses.

1990; Cavuş and Teyler, 1996; Boric et al., 2008; Yang et al., 2013). However, other types of conditioning revealed nonadditive interactions between these two LTP forms in the CA3 $\rightarrow$ CA1 pathway, where LTP induced with prolonged TBS is partially blocked by nifedipine and completely blocked by APV (Morgan and Teyler, 2001). Therefore, we examined LTP induction with multiple TBS epochs in the CA3 $\rightarrow \mathrm{CA} 3$ pathway. As shown in Figure $2 A$, and confirming previous observations (Boric et al., 2008; Yang et al., 2013), in the CA3 $\rightarrow$ CA3 pathway the standard conditioning of 4 epochs of TBS induced robust LTP that is fully blocked by the NMDAR antagonist APV (control: $118 \pm 5 \%, n=8$; APV: $101 \pm$ $4 \%, n=8 ; p=0.008$ ). Notably, when we increased the number of
TBS epochs to 6, the magnitude of the resulting LTP did not change in the presence of APV (control: $116 \pm 5 \%, n=21$; APV: $115 \pm 4 \%, n=10$; Fig $2 B$ ), but the time course did. The presence of APV slowed down the initial development (the first $20 \mathrm{~min}$ ) of 6TBS-LTP, which became similar to mGluR-LTP. In a similar fashion, the L-type $\mathrm{Ca}^{2+}$ channel blocker nifedipine did not affect the magnitude of 6TBS-induced LTP (nifedipene: $113 \pm 1 \%$, $n=8$ ) but changed its time course, which became faster, like NMDAR-LTP. Although none of the drugs applied in isolation affected the final magnitude of 6TBS-LTP, they did block it when coapplied (APV and nifedipine: $101 \pm 2 \%, n=8$ ). The KruskalWallis test confirmed the significance of the differences between the 4 groups $(\mathrm{H}[4,46]=12.56 ; p=0.057)$, and Dunn's post hoc test confirmed that only the APV and nifedipine group was different from control. Thus, in the CA3 $\rightarrow$ CA3 pathway, 6TBS can induce either mGluR-LTP (when NMDARs are blocked) or NMDAR-LTP (when L-type channels are blocked), and in a nonadditive manner: in control conditions (absence of drugs), the magnitude of 6TBS-LTP was not the sum of mGluR-LTP and NMDAR-LTP; rather, the magnitude of the three forms of LTP was similar. On the other hand, we confirmed the nonadditive interactions of the two types of LTP in the CA3 $\rightarrow$ CA1 pathway where 6TBS-LTP induced a large LTP that was fully blocked by APV and partially blocked by nifedepine (control: $155 \pm 6 \%$, $n=29$; APV: $98 \pm 2 \%, n=12$; nifedepine: $123 \pm 8 \%, n=17$; $\mathrm{H}[3,58]=30.76 ; p<0.0001$; Fig. $2 C)$. The observation that the two types of LTP are not additive in both the CA3 $\rightarrow$ CA 1 and the $\mathrm{CA} 3 \rightarrow \mathrm{CA} 3$ pathways suggests that they interact at some level.

Role of fragile $\mathrm{X}$ mental retardation protein (FMRP) and Arc in the induction of mGluR-LTP

The induction of mGluR-LTD and mGluR-LTP depends on intact protein synthesis and stimulation of Type I mGluRs. These common requirements prompted us to determine whether downstream molecules known to mediate and control mGluRLTD also play a role in mGluR-LTP. These studies were done in transgenic mouse lines maintained in a BL6 background. Therefore, we confirmed that in BL6 the LTP induced by the $200 \mathrm{~Hz}$ protocol in the presence of APV is blocked by mGluR antagonists (MEP + LY: $108 \pm 8 \%, n=17$; control: $135 \pm 5, n=12 ; p=$ 0.0059 . Not shown), and by the L-type blocker nifedepine (nifedepine: $107 \pm 5 \%, n=14$; control $133 \pm 9, n=19 ; p=$ 0.0139. Not shown). First, we examined FMRP, a regulator of dendritic protein synthesis, whose genetic deletion removes the vulnerability of mGluR-LTD to translation blockers and increases its magnitude (Huber et al., 2002; Nosyreva and Huber, 2006; Waung and Huber, 2009). We tested this possibility in the $\mathrm{CA} 3 \rightarrow$ CA1 synapses of FMRP KO mice. We found that the protein synthesis inhibitor anisomicyn (anisomicyn: $10 \mu \mathrm{M}$ ), which blocks mGluR-LTP in wild-type mice (DMSO control: $123 \pm$ $3 \%, n=4$ mice, 14 slices; anisomicyn: $100 \pm 1 \%, n=4,13$; Fig. $3 A$ ), did not affect it in the FMRP KO mice (DMSO control: $129 \pm 3 \%, n=4,14$; anisomicyn: $127 \pm 2 \%, n=4,14$. Fig. $3 B)$. These differences were significant $(\mathrm{H}[4,55]=31.77 ; p<0.0001)$. The slight increase in the magnitude of mGluR-LTP in the FMRP KO did not reach the conventional significance criteria. Next, we examined the role of the immediate early gene Arc in the $\mathrm{KO}$ mice. Previous studies have implicated Arc in AMPAR endocytosis, and its genetic deletion completely blocks mGluR-LTD, but not NMDAR-LTD (Park et al., 2008; Waung et al., 2008). One reasonable expectation is that, to the extent that LTP and LTD are opposite processes, the deletion of Arc, which impairs mGluRLTD, should enhance mGluR-LTP. Surprisingly while mGluR- 
A

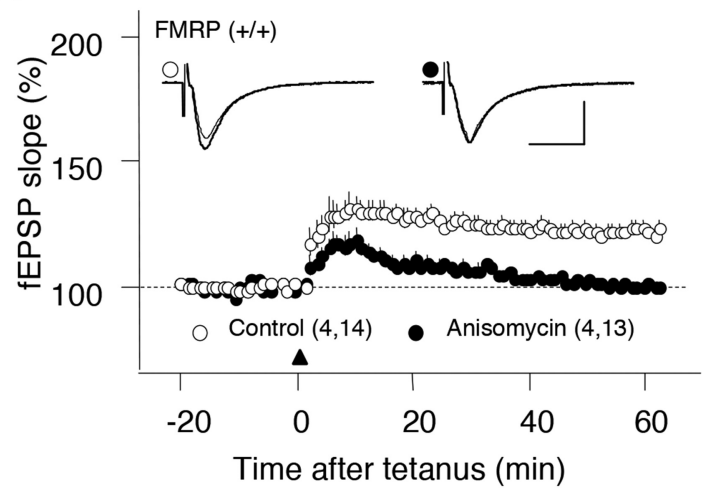

C

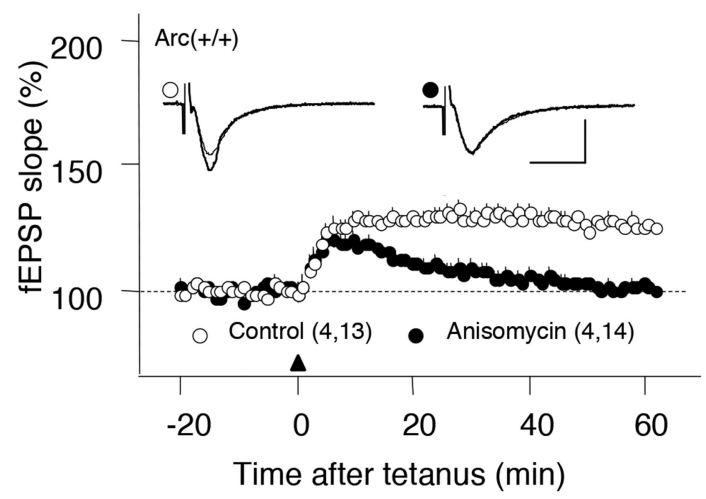

B

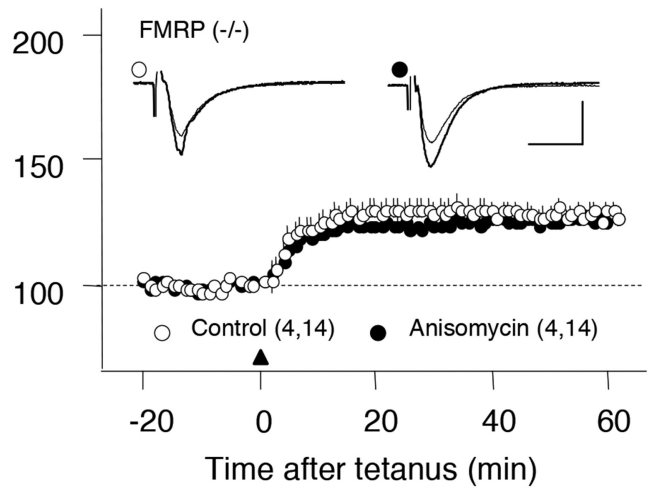

D

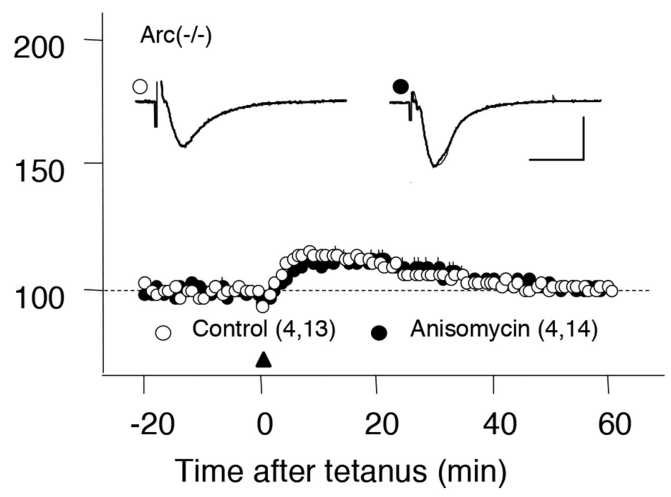

Figure 3. Role of FMRP and Arc in the induction of $m G l u R-L T P$ in CA1 $\rightarrow$ CA3 synapses. The induction mGluR-LTP with $200 \mathrm{~Hz}$ tetanus is blocked by the translation inhibitor anisomycin in control FMRP $^{(+/+)}$mice $(\boldsymbol{A})$ but not in FMRP ${ }^{(-/-)}$mice $(\boldsymbol{B}) . \boldsymbol{C}, \boldsymbol{D}$, Role of Arc. Only the transient potentiation normally observed in Arc ${ }^{(+/+)}$mice after blockade of protein synthesis $(\boldsymbol{C})$ is induced in $\operatorname{Arc}^{(-I-)}$ mice. Superimposed traces in each represent example experiments. Each trace represents the average of 10 responses recorded before (thin traces) and 60 min after the tetanus (thick traces). Calibration: $1 \mathrm{mV}, 10 \mathrm{~ms}$. The number of mice and experiments is indicated in parentheses.

LTP was robust and blocked by anisomicyn in the wild types (DMSO control: $126 \pm 2 \%, n=4,13$; anisomicyn: $101 \pm 1 \%, n=$ 4,14; Fig. 3C), mGluR-LTP was completely eliminated in the Arc $\mathrm{KO}$, where the high-frequency tetanus (in APV) induced only a transient and modest post-tetanic potentiation similar to that observed under protein synthesis blockade (DMSO control: $101 \pm 1 \%, n=4,13$; anisomicyn: $101 \pm 1 \%, n=4,14, p=0.858$; Fig. $3 D)$. These differences were significant $(\mathrm{H}[4,54]=31.77$; $p<0.0001)$.

Finally, we used immunocytochemistry to determine whether the $200 \mathrm{~Hz}$ tetanus in the presence of APV increases Arc protein in CA1. These experiments were performed in minislices with the CA3/DG subfields removed: half of the minislices were tetanized, whereas paired control minislices received only baseline stimulation. At 25-30 min later, the slices were collected and processed for immunobloting. As shown in Figure 4, Arc protein content was significantly larger in the tetanized slices (tetanized: $0.463 \pm$ 0.028; control: $0.361 \pm 0.024, n=17$ pairs, $p=0.0095)$. Together, these results indicate that mGluR-LTP and mGluR-LTD do share a substantial portion of the initial steps on their induction cascade, including Arc signaling.

\section{Discussion}

The present examination of the induction of an LTP form previously described as VGCC-LTP revealed that it depends also on the stimulation of Type I mGluRs, on the integrity of Arc signaling, and on protein synthesis controlled by FMRP. Notably, these mechanistic requirements are also common to the induction of mGluR-LTD (Huber et al., 2002; Nosyreva and Huber, 2006;
Park et al., 2008). Thus, in the absence on NMDAR activity, mGluR stimulation cannot only decrease synaptic strength (see Lüscher and Huber, 2010) but also increase it, and both processes involve Arc signaling. Based on these observations, we propose the coexistence of two distinct mechanisms of activity-dependent synaptic plasticity: one reads NMDAR activity and the other one reads Type I mGluR activity.

Previous studies revealed clear differences in the induction cascades of NMDAR-LTP and mGluR-LTP. From the outset, NMDAR-LTP does not require mGluRs (Selig et al., 1995), whereas mGluR-LTP does not require NMDARs (Grover and Teyler, 1990). Downstream from there, the two forms of LTP depend on different sets of initial kinases (Cavuş and Teyler, 1996), although they appear to converge on the MAPK cascade (Kanterewicz et al., 2000). Consistent with the notion of different induction cascades, we found that mGluR-LTP requires intact protein synthesis and Arc signaling, which is not the case in NMDAR-LTP induction. These two processes are crucial for the consolidation of NMDAR-LTP into a long-lasting form of plasticity (Plath et al., 2006; Bramham, 2008) but are not required for its initial induction. In that regard, it would be of interest to determine whether protein synthesis-dependent mGluR-LTP is long lasting. Another remaining open question is how protein synthesis and Arc signaling are required for both mGluR-LTP and mGluR-LTD. Although the issue is puzzling, a common intermediate for LTP and LTD is not unusual. For example, there is evidence that NMDAR-LTP and NMDAR-LTD both depend on the activation of CaMKII (Stevens et al., 1994; Coultrap et al., 

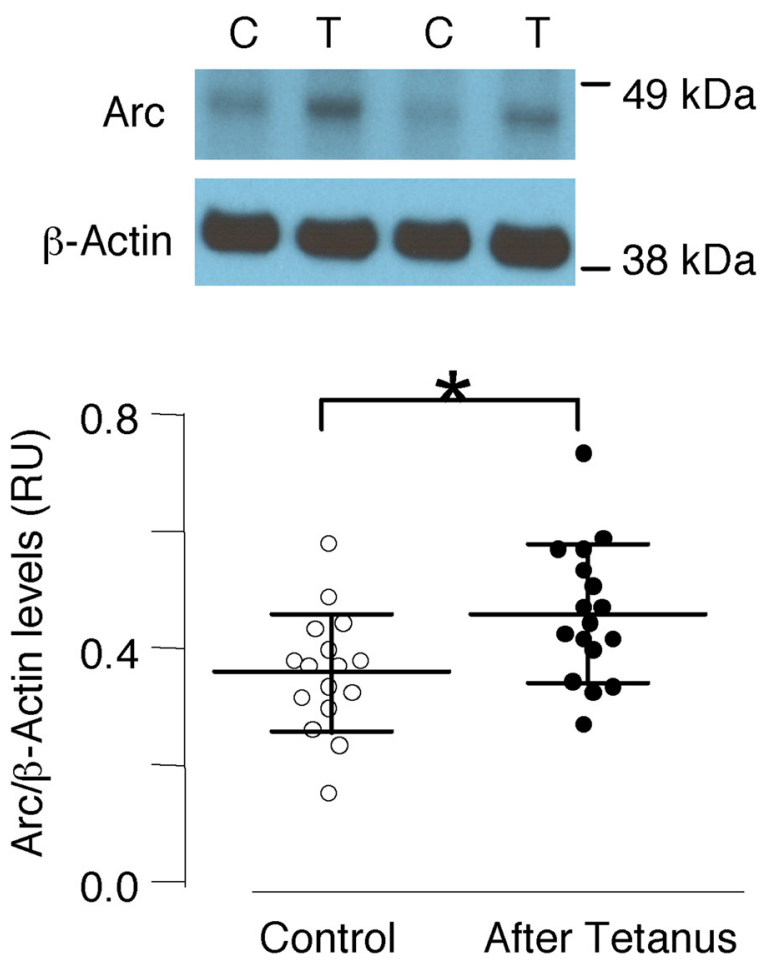

Figure 4. Increase in Arc protein after $200 \mathrm{~Hz}$ tetanus. Western blot analysis of Arc expression in control (open circle) and tetanized (black circles) slices. Arc levels were relativized to $\beta$-actin through densitometry analysis and presented as relative units (RU). Individual data points are laterally displaced for illustrative purposes. Horizontal bars indicate mean \pm SEM. ${ }^{*} p<0.01$. Top, Example blots from control (C) and tetanized (T) minislices.

2014). Similarly, as mentioned, Arc signaling has been implicated in the induction of mGluR-LTD (Park et al., 2008) and in the maintenance of NMDAR-LTP (Plath et al., 2006). In sum, the differences in mechanism between mGluR-LTP and NMDARLTP, and the similarities with mGluR-LTD fit nicely with the notion that NMDARs and mGluRs can activate two distinct systems of synaptic plasticity. In this light, it would be interesting to consider whether mGluR-LTP is also involved in some of the processes where mGluR-LTD has been implicated, such as encoding novelty and learning deficits associated with the fragile $\mathrm{X}$ condition (for review, see Bear et al., 2004; Lüscher and Huber, 2010).

Activation of Type I mGluRs can result in either LTP or LTD through a common initial pathway that depends on protein synthesis, FMRP and Arc signaling. This raises the question of what specifies the polarity of mGluR-dependent synaptic plasticity. In the case of NMDAR-dependent plasticity, the prevailing (yet not universal) consensus is that the polarity of the changes is dictated by the magnitude of the initial intracellular $\mathrm{Ca}^{2+}$ signal. The recent demonstration that $\mathrm{mGluR}$-LTD requires an intracellular $\mathrm{Ca}^{2+}$ increase (Kim et al., 2015) renders the $\mathrm{Ca}^{2+}$ magnitude hypothesis a plausible mechanism for mGluR-dependent plasticity also.

The observation that mGluR-LTP and NMDAR-LTP can interact (Fig. 2B) suggests that these two forms of LTP can coexist in the same synapse, or at least in close proximity, like NMDARLTD and mGluR-LTD (Oliet et al., 1997) coexist in CA1 synapses. The functional consequences of having two coexisting systems of plasticity remain to be explored. One clear difference between these two systems is that in vitro the induction of mGluR-dependent plasticity requires more presynaptic activity than the induction of NMDAR-dependent plasticity. Induction of mGluR-LTP requires tetanus of higher frequency and longer duration than NMDAR-LTP. Similarly, although both forms of LTD are induced with prolonged low-frequency stimulation, mGluR-LTD is typically induced with twice the stimulation pulses as NMDAR-LTD (Oliet et al., 1997; Huber et al., 2000). These observations open the consideration that these two plasticity systems operate at different levels of neural activity, with mGluR-dependent plasticity being recruited at higher levels of activity. For example, the changes in the correlation between presynaptic and postsynaptic activity are likely computed by the NMDAR-based system when the overall levels of activity are low to moderate. At a higher firing regimen, the NMDAR-based system might saturate and the mGluR-mediated plasticity would be better suited to subserve the function. This two dynamic ranges scenario resonates nicely with the observation that, in the aged hippocampus, which typically expresses high levels of firing rates and excitability, mGluR-dependent plasticity becomes crucial for learning performance (Lee et al., 2005; Boric et al., 2008; Ménard and Quirion, 2012a,b; Yang et al., 2013). In sum, the realization that Type I mGluRs can support bidirectional synaptic plasticity in similar fashion as previously demonstrated for NMDARdependent plasticity opens questions that are highly significant for our understanding of learning and memory formation.

\section{References}

Abraham WC (2008) Metaplasticity: tuning synapses and networks for plasticity. Nat Rev Neurosci 9:387. CrossRef Medline

Bear MF, Huber KM, Warren ST (2004) The mGluR theory of fragile X mental retardation. Trends Neurosci 27:370-377. CrossRef Medline

Boric K, Muñoz P, Gallagher M, Kirkwood A (2008) Potential adaptive function for altered long-term potentiation mechanisms in aging hippocampus. J Neurosci 28:8034-8039. CrossRef Medline

Bramham CR (2008) Local protein synthesis, actin dynamics, and LTP consolidation. Curr Opin Neurobiol 18:524-531. CrossRef Medline

Casimiro TM, Sossa KG, Uzunova G, Beattie JB, Marsden KC, Carroll RC (2011) mGluR and NMDAR activation internalize distinct populations of AMPARs. Mol Cell Neurosci 48:161-170. CrossRef Medline

Cavuş I, Teyler T (1996) Two forms of long-term potentiation in area CA1 activate different signal transduction cascades. J Neurophysiol 76: 3038-3047. Medline

Coultrap SJ, Freund RK, O’Leary H, Sanderson JL, Roche KW, Dell'Acqua ML, Bayer KU (2014) Autonomous CaMKII mediates both LTP and LTD using a mechanism for differential substrate site selection. Cell Rep 6:431-437. CrossRef Medline

Fidzinski P, Shor O, Behr J (2008) Target-cell-specific bidirectional synaptic plasticity at hippocampal output synapses. Eur J Neurosci 27:1111-1118. CrossRef Medline

Grover LM, Teyler TJ (1990) Two components of long-term potentiation induced by different patterns of affeent activation. Nature 347:477-479. CrossRef Medline

Hsieh H, Boehm J, Sato C, Iwatsubo T, Tomita T, Sisodia S, Malinow R (2006) AMPAR removal underlies Abeta-induced synaptic depression and dendritic spine loss. Neuron 52:831-843. CrossRef Medline

Huber KM, Gallagher SM, Warren ST, Bear MF (2002) Altered synaptic plasticity in a mouse model of fragile $\mathrm{X}$ mental retardation. Proc Natl Acad Sci U S A 99:7746-7750. CrossRef Medline

Huber KM, Kayser MS, Bear MF (2000) Role for rapid dendritic protein synthesis in hippocampal mGluR-dependent long-term depression. Science 288:1254-1257. CrossRef Medline

Huganir RL, Nicoll RA (2013) AMPARs and synaptic plasticity: the last 25 years. Neuron 80:704-717. CrossRef Medline

Kanterewicz BI, Urban NN, McMahon DB, Norman ED, Giffen LJ, Favata MF, Scherle PA, Trzskos JM, Barrionuevo G, Klann E (2000) The extracellular signal-regulated kinase cascade is required for NMDA receptorindependent LTP in area CA1 but not area CA3 of the hippocampus. J Neurosci 20:3057-3066. Medline

Kim HH, Lee KH, Lee D, Han YE, Lee SH, Sohn JW, Ho WK (2015) Costimulation of AMPA and metabotropic glutamate receptors underlies 
phospholipase C activation by glutamate in hippocampus. J Neurosci 35:6401-6412. CrossRef Medline

Lee HK, Min SS, Gallagher M, Kirkwood A (2005) NMDA receptorindependent long-term depression correlates with successful aging in rats. Nat Neurosci 8:1657-1659. CrossRef Medline

Lüscher C, Huber KM (2010) Group 1 mGluR-dependent synaptic longterm depression: mechanisms and implications for circuitry and disease. Neuron 65:445-459. CrossRef Medline

Ménard C, Quirion R (2012a) Group 1 metabotropic glutamate receptor function and its regulation of learning and memory in the aging brain. Front Pharmacol 3:182. CrossRef Medline

Ménard C, Quirion R (2012b) Successful cognitive aging in rats: a role for mGluR5 glutamate receptors, homer 1 proteins and downstream signaling pathways. PLoS One 7:e28666. CrossRef Medline

Morgan SL, Teyler TJ (2001) Electrical stimuli patterned after the thetarhythm induce multiple forms of LTP. J Neurophysiol 86:1289-1296. Medline

Morris RG (2013) NMDA receptors and memory encoding. Neuropharmacology 74:32-40. CrossRef Medline

Nosyreva ED, Huber KM (2006) Metabotropic receptor-dependent longterm depression persists in the absence of protein synthesis in the mouse model of fragile X syndrome. J Neurophysiol 95:3291-3295. CrossRef Medline

Oliet SH, Malenka RC, Nicoll RA (1997) Two distinct forms of long-term depression coexist in CA1 hippocampal pyramidal cells. Neuron 18: 969-982. CrossRef Medline

Park S, Park JM, Kim S, Kim JA, Shepherd JD, Smith-Hicks CL, Chowdhury S, Kaufmann W, Kuhl D, Ryazanov AG, Huganir RL, Linden DJ, Worley PF (2008) Elongation factor 2 and fragile X mental retardation protein control the dynamic translation of Arc/Arg3.1 essential for mGluR-LTD. Neuron 59:70-83. CrossRef Medline
Plath N, Ohana O, Dammermann B, Errington ML, Schmitz D, Gross C, Mao X, Engelsberg A, Mahlke C, Welzl H, Kobalz U, Stawrakakis A, Fernandez E, Waltereit R, Bick-Sander A, Therstappen E, Cooke SF, Blanquet V, Wurst W, Salmen B, et al. (2006) Arc/Arg3.1 is essential for the consolidation of synaptic plasticity and memories. Neuron 52:437-444. CrossRef Medline

Selig DK, Lee HK, Bear MF, Malenka RC (1995) Reexamination of the effects of MCPG on hippocampal LTP, LTD, and depotentiation. J Neurophys 74:1075-1082. Medline

Stevens CF, Tonegawa S, Wang Y (1994) The role of calcium-calmodulin kinase II in three forms of synaptic plasticity. Curr Biol 4:687-693. CrossRef Medline

Volk LJ, Daly CA, Huber KM (2006) Differential roles for group 1 mGluR subtypes in induction and expression of chemically induced hippocampal long-term depression. J Neurophysiol 95:2427-2438. CrossRef Medline

Waung MW, Huber KM (2009) Protein translation in synaptic plasticity: mGluR-LTD, Fragile X. Curr Opin Neurobiol 19:319-326. CrossRef Medline

Waung MW, Pfeiffer BE, Nosyreva ED, Ronesi JA, Huber KM (2008) Rapid translation of Arc/Arg3.1 selectively mediates mGluR-dependent LTD through persistent increases in AMPAR endocytosis rate. Neuron 59: 84-97. CrossRef Medline

Yang S, Megill A, Ardiles AO, Ransom S, Tran T, Koh MT, Lee HK, Gallagher M, Kirkwood A (2013) Integrity of mGluR-LTD in the associative/commissural inputs to CA3 correlates with successful aging in rats. J Neurosci 33:12670-12678. CrossRef Medline

Zhang W, Wu J, Ward MD, Yang S, Chuang YA, Xiao M, Li R, Leahy DJ, Worley PF (2015) Structural basis of arc binding to synaptic proteins: implications for cognitive disease. Neuron 86:490-500. CrossRef Medline 